\title{
Affinity purification of recombinant human plasminogen activator from transgenic rabbit milk using a novel polyol- responsive monoclonal antibody
}

\author{
Shaozheng Song ${ }^{1,2}$, Zhengyi He ${ }^{1}$, Junyan Mei $^{1}$, Zhengqiang Qi ${ }^{1}$, Si Chen ${ }^{1}$, \\ Sheng $\mathrm{Xu}^{1}$, Yuguo Yuan ${ }^{1,2}$ and Yong Cheng ${ }^{1,2 \star}$ \\ ${ }^{1}$ Engineering Research Centre for Transgenic Animal Pharmaceutics in Jiangsu Province, College of Veterinary Medicine, \\ Yangzhou University, ${ }^{2}$ Jiangsu Co-innovation Center for Prevention and Control of Important Animal Infectious Diseases and \\ Zoonoses, Yangzhou, China
}

*For correspondence: Email: ssz0610@126.com; Tel: +8615906181002

\begin{abstract}
Purpose: To develop processes for effective isolation and purification of recombinant human plasminogen activator (rhPA) from transgenic rabbit milk.

Methods: Immunoaffinity chromatography was selected and improved by a special polyol-responsive monoclonal antibody (PR-mAb). Alteplase was used as immunogen because of its similarity to rhPA in terms of structure. The PR-mAb was prepared by hybridoma technology and screened by ELISA-elution assay. Screening antibody was performed using rhPA milk in an ELISA-elution assay. The antibody clone C4-PR-mAb was selected for immunoaffinity chromatography. The rhPA was effectively bound to immobilized C4-PR-mAb on the column and was eluted with Tris buffer comprising $0.75 \mathrm{~mol} / \mathrm{L}$ ammonium sulfate and 40n\% propanediol (pH7.9). The rhPA was further purified by passing through Chromdex75 gel filtration column.

Results: There were 12 hybridoma strains selected into the polyol-responsive mAbs screen step and three hybridoma strains were superior for producing PR-mAbs (C1, C4, C8). The rhPA can be purified from transgenic rabbit milk and maintained a higher thrombolytic activity in vitro by FAPA.

Conclusion: The results demonstrate the suitability of the alternative approach used in this study. Using immunoaffinity chromatography and gel filtration column is feasible and convenient for extracting rhPA from milk, and should be useful for purifying other tPA mutants or other novel recombinant milkderived proteins.
\end{abstract}

Keywords: tPA, Immunoaffinity chromatography, PR-mAb, ELISA-elution, Antibody, Thrombolytic activity

Tropical Journal of Pharmaceutical Research is indexed by Science Citation Index (SciSearch), Scopus, International Pharmaceutical Abstract, Chemical Abstracts, Embase, Index Copernicus, EBSCO, African Index Medicus, JournalSeek, Journal Citation Reports/Science Edition, Directory of Open Access Journals (DOAJ), African Journal Online, Bioline International, Open-J-Gate and Pharmacy Abstracts

\section{INTRODUCTION}

Natural human tissue plasminogen activator (tPA) is secreted by vascular endothelial cells displaying thrombolytic activity. Currently on the market, clinical tPA is used for treating acute myocardial infarction, brain death, pulmonary embolism, deep venous thrombosis, and other thrombotic diseases and is produced by prokaryotic or eukaryotic cell expression system (e.g., CHO) [1-3]. Some modifications on molecular structure have resulted in recombinant tPA (rtPA or rhPA) with better bioactive characters, such as higher specificity to thrombus, longer half-life in blood, and less amount of bleeding [1,2]. However, commonly 
used processes for rhPA are based on prokaryotic or eukaryotic vector which impose many limitations on rhPA development, i.e., its technology and cost $[1,4]$.

To increase the half-life and thrombolytic activity of tPA-type drugs, a novel tPA mutant (rhPA) was designed by our research team. With only $\mathrm{K} 2$ and $\mathrm{P}$ structure domain, it was different from Alteplase, which contains $F, E, K 1, K 2$, and $P$ domains. It was produced by using a transgenic rabbit mammary gland bioreactor, which may be a popular approach for expressing recombinant foreign protein more safely. This bioreactor also produces higher output than prokaryotic or eukaryotic cell expression system. If its purity is further improved, and its activity is preserved in the manufacturing process, rhPA has great potential as a new application in thrombolytic medicine. However, effective purification for this novel recombinant protein is needed.

Many methods of protein extraction from milk have been studied [5,6], among which immuno affinity chromatography(IAC) is a convenient and efficient approach because of its simple one-step operation and high specificity to target protein $[7,8]$. However, a strongly acidic buffer $(\mathrm{pH}$ is less than or equal to 3.0) is often used to elute and dissociate the target protein, which was not beneficial in protecting the molecular conformation and bioactivity of rhPA.

In order to preserve the functional domains, it would be best to assemble an affinity column that allows protein dissociation from immobilized ligand. Polyol-responsive monoclonal antibody (PR-mAb) is a kind of special ligand that can release the target protein from the IAC column gently and easily [8]. The application of PR-mAbs to the affinity column would improve the defects because of its slightly alkaline elution buffer instead of strong acidic condition, consisting of Tris buffer with ammonium sulfate and propylene glycol $(\mathrm{pH} 7.9)$ which have little damage to protein stability [9].

Preparation of specific antibodies is very important in affinity technology; finding a suitable immunogen is a key link. Alteplase, a commercial drug, can be used as immunogen for anti-rhPA antibodies, which has a structure similar to that of rhPA and can be obtained with high purity (> $99 \%)$.However, to prepare specific antibody for rhPA, Alteplase was used as the immunogen. After conducting the Elisa-elution screening method, three strains of PR-mAbs were successfully obtained.

\section{EXPERIMENTAL}

This study was approved by the Institutional Animal Care and Use Committee of Yangzhou University (China) and performed according to the Guide for the care and use of laboratory animals [10]. Chemicals were purchased from Sigma Chemical Co. and China unless otherwise specified.

\section{Immunization and hybridoma cell culture}

Six-week old BALB/c mice were immunized by Alteplase (purchased from Subei People's Hospital of Jiangsu province, China). QuickAntibody ${ }^{\mathrm{TM}}$ immunologic adjuvant was used to enhance the immune response of Alteplase, mixed with Alteplase of 1:1 volume. Each mouse was injected intramuscularly with $5 \mu \mathrm{g}$ mixture of Alteplase-QuickAntibody twice, at an interval of 21 days. At 14 days after the secondary immunization, booster injection was given intramuscularly with Alteplase-PBS solution at 10 $\mu \mathrm{g}$ per mouse. Three days after booster injection, the mouse that presented higher serum level of antibodies was selected for cell fusion.

Electro fusion technique was used in cell fusion. However, spleen cells and myeloma cells were mixed at a ratio of $1: 1$ and fused in electro fusion solution (0.3 M mannitol, $0.1 \mathrm{mM} \mathrm{CaCl}_{2}$, and 0.1 $\mathrm{mM} \mathrm{MgCl}_{2}$ ) using cell fusion generator. The distance between the two electrodes was $2 \mathrm{~mm}$. Membrane fusion was performed by three electrical pulses; first with alternating current at $40 \mathrm{~V}$ for $30 \mathrm{~s}$ and then with two times of direct current at $325 \mathrm{~V}(162.5 \mathrm{~V} / \mathrm{mm})$ for $30 \mu$ sat an interval time of $0.5 \mathrm{~s}$. The fused cells were centrifuged (800 $\mathrm{g}, 5 \mathrm{~min}$ ) and the cell pellets were suspended with HAT/DMEM medium and planted into 96-well platespre-coated with feeder cells.

\section{Screening for anti-rhPA mAbs}

Indirect ELISA was used here. The rhPA milk whey of transgenic rabbit was immobilized to ELISA plate as the detecting antigen. In another ELISA plate, the normal rabbit milk whey was immobilized as control antigen to exclude the false positive results that would be caused by the nonspecific binding of antibodies to other components from rabbit whey. The supernatant of each cell culture was the primary antibody, SP20 cell culture acted as negative control, and PBS acted as blank control. After three times subcloning by limited dilution assay, positive hybridoma could be determined. 


\section{Screening for PR-mAbs}

ELISA-elution assay was performed as described previously [12]. Here, the rhPA milk whey was immobilized, cross-reacting with the primary antibody (supernatant of positive hybridoma cells) for $2 \mathrm{~h}$ at $37^{\circ} \mathrm{C}$. SP20 cell culture acted as negative control, and PBS acted as blank control. After washing, Tris buffer containing $0.75 \mathrm{M}$ ammonium sulfate and $40 \%(\mathrm{v} / \mathrm{v})$ propylene glycol ( $\mathrm{pH}$ 7.9) was added to each sampling hole and kept at room temperature $\left(24^{\circ} \mathrm{C}\right)$ for $20 \mathrm{~min}$ to dissociate the binding of antibody to antigen. The secondary antibody (HRP conjugated goat anti-mouse IgG antibody) was diluted with dilution buffer (PBS with $1 \%$ FBS) at a volume ratio of 1:2000. After color development, each well was read by microplate reader at $450 \mathrm{~nm}$.

\section{Large scale preparation and purification for PR-mAb}

Eight-week old multiparous BALB/c mice were intraperitoneally injected with $0.5 \mathrm{~mL}$ liquid paraffin,followed by the PR-mAb hybridoma cells of $5 \times 10^{6}$ cells per mouse 1 week later. After 5 days, peritoneal fluid was collected and purified by ProteinA affinity column.

\section{Preparation for immunoaffinity column}

The purified antibody was dialyzed with $3.5 \mathrm{KDa}$ molecular weight cutoff dialytic-bags against coupling buffer $\left(0.2 \mathrm{M} \mathrm{NaHCO}_{3}, 0.5 \mathrm{M} \mathrm{NaCl}\right)$ overnight at $4{ }^{\circ} \mathrm{C}$ and concentrated via PEG20000. This antibody solution was transferred to the CNBr activated Sepharose for conjugation. The process was performed at room temperature $\left(24{ }^{\circ} \mathrm{C}\right)$ overnight, whereas the uncoupled $\mathrm{CNBr}$ groups were blocked in the blocking buffer (20 mM Tris- $\mathrm{HCl}, \mathrm{pH} 8.3)$ for $4 \mathrm{~h}$ at the same temperature. Before the resin could be used, $0.05 \mathrm{M}$ Tris- $\mathrm{HCl}(\mathrm{pH} 8.5)$ and $0.2 \mathrm{M}$ acetate $(\mathrm{pH}$ 4.6) were used to wash the mAbSepharosesix times alternately. Finally, precooled PBS was transferred to suspend the resin.

\section{Purification of rhPA using the immunoaffinity column}

Before application to the IAC, milk sample was processed as follows rabbit milk was centrifuged $(8,000 \mathrm{rpm})$ at $4{ }^{\circ} \mathrm{C}$ for $30 \mathrm{~min}$ and the supernatant of whey was separated from transgenic rabbit milk; $35 \%$ saturated ammonium sulfate was added to the supernatant for precipitating the rhPA component and then the pellet was dialyzed with $3.5 \mathrm{KDa}$ molecular weight cutoff dialytic-bags against PBS overnight at $4^{\circ} \mathrm{C}$.

After pretreatment on milk, the crude sample was run on the C4-PR-mAb coupled column. AKTA explorer system with UV detector $(280 \mathrm{~nm})$, sample loops, fraction collector and analysis software was used in the IAC. The packed column was washed and equilibrated with PBS at $1 \mathrm{~mL} / \mathrm{min}$. The crude rhPA solution was loaded into the column at a flow speed of $1 \mathrm{~mL} / \mathrm{min}$ and, PBS used to elute the unbinding proteins out of the affinity column. When the flow through the baseline was stable, elution buffer (TE buffer with $0.75 \mathrm{~mol} / \mathrm{L}$ ammonium sulfate and $40 \%$ propanediol, $\mathrm{pH}$ 7.9) was run on the IAC at 1 $\mathrm{mL} / \mathrm{min}$ to dissociate the rhPA from the mAbsepharose. The peak fractions were collected and analyzed by SDS-PAGE.

\section{Further purification of rhPA using gel filtration chromatography}

Chromdex 75 prep grade gel filtration was used to remove the other large proteins. IAC processed sample was run on the gel filtration column and eluted with PBS $(\mathrm{pH} 7.4)$ at 1 $\mathrm{mL} / \mathrm{min}$. The other proteins with larger molecular weight passed through the column first, and the rhPA fraction followed.

\section{Purity, antibody cross-reactivity and thrombolytic activity of the purified rhPA}

SDS-PAGE was used to analyze the purity of rhPA product from immunoaffinity step and gel filtration step.

The unstained gel was applied in Western blot analysis to identify the rhPA. However, the gel was transferred to the 0.45 micrometers PVDF membrane in transfer buffer at $1 \mathrm{~mA} / \mathrm{cm}^{2}$ for 3.5 $\mathrm{h}$, Furthermore, the membrane was placed in blocking buffer at $4{ }^{\circ} \mathrm{C}$ overnight. The primary antibody was the purified PR-mAb, which was diluted at 1:5000 in PBS and incubated with membrane at $37^{\circ} \mathrm{C}$ for $1.5 \mathrm{~h}$. The secondary antibody conjugated with HRP was added and held at $37^{\circ} \mathrm{C}$ for $1.5 \mathrm{~h}$. After washing thrice with washing buffer, DAB substrate solution was used for blot development, and incubation was done for $20 \mathrm{~min}$ at room temperature $\left(24^{\circ} \mathrm{C}\right)$.

ELISA was used to determine the antibody cross-reactivity of each fraction collected from the chromatography process. Procedure for this test was similar to the antibody screening section. However, the coating antigen was replaced with each fraction of chromatography, and the primary antibody was replaced with the 
purified PR-mAb. The other operations were the same as the part of antibody screen.

Fibrin agarose plate assay (FAPA) was carried out to evaluate the thrombolytic activity of the purified rhPA. Fibrin-thrombin-agarose gel (100 $\mathrm{mL}$ ) was composed of $1 \mathrm{~g}$ agarose, $1 \mathrm{~g}$ fibrinogen, and $100 \mathrm{U}$ thrombin dissolved in PBS. Agarose was brought to a boil, and after cooling to $45^{\circ} \mathrm{C}$, boiled agarose was immediately mixed with fibrinogen and thrombin $\left(37^{\circ} \mathrm{C}\right)$. The warm mixture was then dispensed into Plexiglass dishes. When the solution cooled to room temperature, fibrin-thrombin-agarose solidified to a gel state. Sample wells were drilled in each gel and filled with $20 \mu \mathrm{L}$ sample solution. In thrombolytic step, each dish was incubated at 37 ${ }^{\circ} \mathrm{C}$ overnight. The activity was determined by the diameter size of the thrombin-dissolving ring.

\section{Statistical analysis}

Data analysis was performed by descriptive analysis and standard curve using SPSS 21 (SPSS Institute, Cary, NC, USA).

\section{RESULTS}

\section{Preparation of anti-rhPA monoclonal antibody}

QuickAntibodyTM adjuvant was used in mouse immunization. After boost immunization, the serum titer reached 1:1010. In this study, the dose of immunogen was reduced to $20 \mu \mathrm{g}$ per mouse, and the experimental days were shortened to 35 days. Improvements in immune dose and period were observed with the above mentioned procedure compared with the common Freund's adjuvant procedure.

A total of 814 hybridoma clones appeared in a96well plate. Standard ELISA was used to screen positive cell strains producing antibodies that could react with the coating antigen, rabbit milk, which contained rhPA. After three times of subcloning, 12 hybridoma strains were selected for the polyol-responsive mAbs screen step.

\section{Screening of polyol-responsive monoclonal antibody}

The 12 positive hybridomas detected in standard ELISA were rescreened here. Comparing the OD value of the two kinds of ELISA, the wells with a significantly decrease in OD were considered to contain polyol responsive mAbs. According to Table1, three hybridoma strains were superior in terms of producing PR-mAbs, as follows: C1, C4, and $\mathrm{C} 8$. The values of D-OD reached $50 \%$ $[10,12]$.

C4 hybridoma strain was selected to prepare the $\mathrm{PR}-\mathrm{mAb}$ for immunoaffinity ligand. ProteinA column was used to purify the C4 PR-mAb from mouse ascites.

\section{Immunoaffinity purity of rhPA in rabbit milk}

SDS-PAGE gel showed the sample with other two bands at $55-70 \mathrm{KDa}$, which were not the molecular weight of rhPA (Figure 1). This result suggested that the fraction contained proteins, but not rhPA.

Therefore, gel filtration chromatography was applied to separate the other unrelated proteins. According to the principle of molecular sieve, the large protein was first passed through the column. rhPA, which had smaller molecular weight was considered in the second peak $b$ (Figure 2). SDS-PAGE showed the peak $b$ fraction only with a single band, and the band was allocated at $39 \mathrm{KDa}$, which was the molecular weight of rhPA (Figure 1). Further determination of crosslink activity for the fraction of peak $b$ was performed by Western Blot (Figure 1). The results suggested that the target protein rhPA was contained in the second peak b.

Table 1: ELISA-elution of polyol-responsive monoclonal antibody to rhPA

\begin{tabular}{lcccccccccccccc}
\hline Cell line & C1 & C2 & C3 & C4 & C5 & C6 & C7 & C8 & C9 & C10 & C11 & C12 & $\begin{array}{l}\text { SP2 } \\
\text { /0 }\end{array}$ & $\begin{array}{l}\text { PB } \\
\text { S }\end{array}$ \\
\hline OD1 & 3.1 & 1.2 & 1.3 & 3.7 & 2.9 & 1.8 & 1.7 & 1.1 & 2.0 & 1.3 & 2.2 & 1.0 & 0.06 & 0.0 \\
& 75 & 64 & 00 & 27 & 23 & 05 & 66 & 79 & 12 & 21 & 26 & 73 & 0 & 63 \\
OD2 & 1.0 & 0.8 & 1.3 & 0.9 & 2.3 & 0.9 & 1.7 & 0.0 & 1.4 & 1.0 & 1.8 & 0.8 & 0.06 & 0.0 \\
& 72 & 23 & 53 & 32 & 47 & 38 & 95 & 58 & 37 & 02 & 45 & 96 & 1 & 58 \\
\multirow{2}{*}{ OD } & 2.1 & 0.4 & & 2.7 & 0.5 & 0.8 & & 1.1 & 0.5 & 0.3 & 0.3 & 0.1 & - & - \\
& 03 & 41 & - & 95 & 76 & 67 & - & 21 & 75 & 19 & 81 & 77 & - & - \\
D-OD(\%) & 66. & 34. & & 75. & 19. & 48. & & 95. & 28. & 24. & 17. & 16. & - & - \\
& 20 & 90 & 0 & 00 & 70 & 00 & 0 & 10 & 60 & 10 & 10 & 50 & & \\
\hline
\end{tabular}

The coating antigen is transgenic rabbit milk. SP20 cell acted as negative control. PBS acted as blank control. $O D 1$ is the optical density of standard ELISA. OD2 is the optical density of ELISA-elution. $\triangle O D$ is equal to OD2 minus OD1; $D-O D$ is equal to $\triangle O D / O D 1 * 100 \%$ 


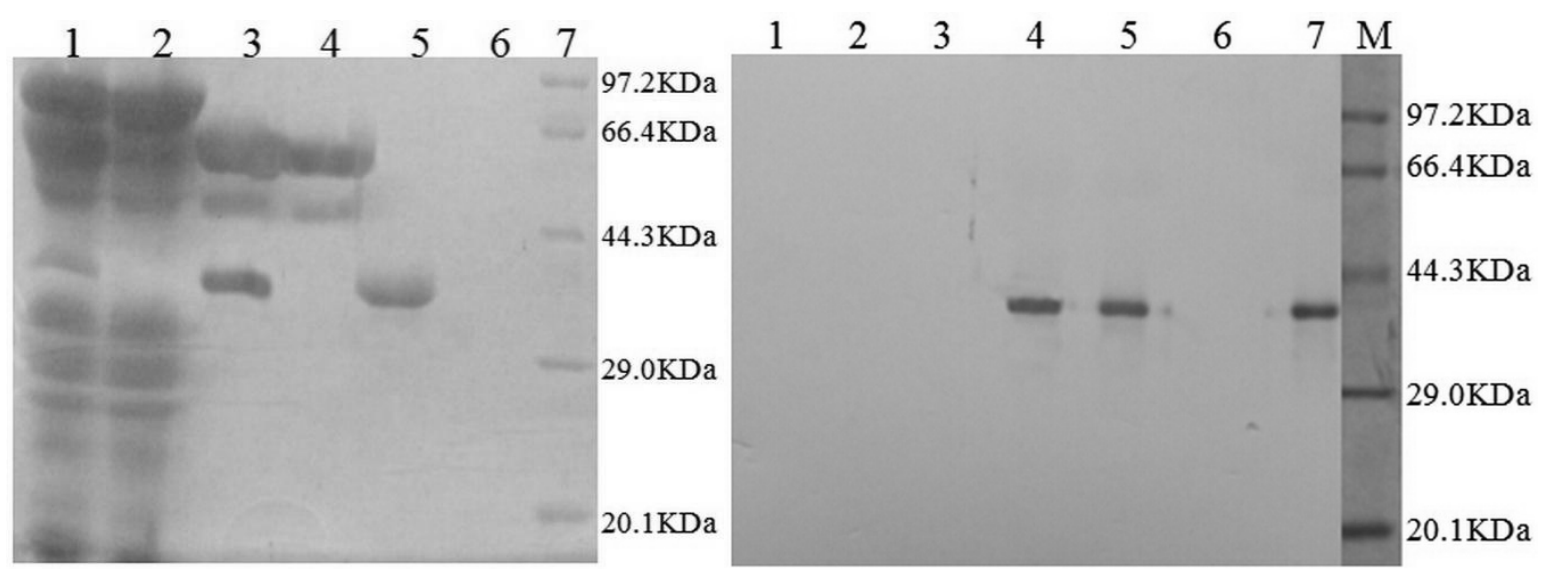

Figure 1: SDS-PAGE and Western Blot analysis in the purification of rhPA. Note: Part A, from 1 to 7 , the electrophoresis bands arewhey of transgenic rabbit milk, whey of normal non-transgenic rabbit milk, product of affinity chromatography, peak a in gel filtration chromatography, peak $b$ in gel filtration chromatography, and PBS respectively; Part $B$, from 1 to $M$, the electrophoresis bands were PBS, water, whey of normal non-transgenic rabbit milk, whey of transgenic rabbit milk, products in affinity chromatography, peak a in gel filtration chromatography, peak $b$ in gel filtration chromatography, and the protein of molecular weight standards

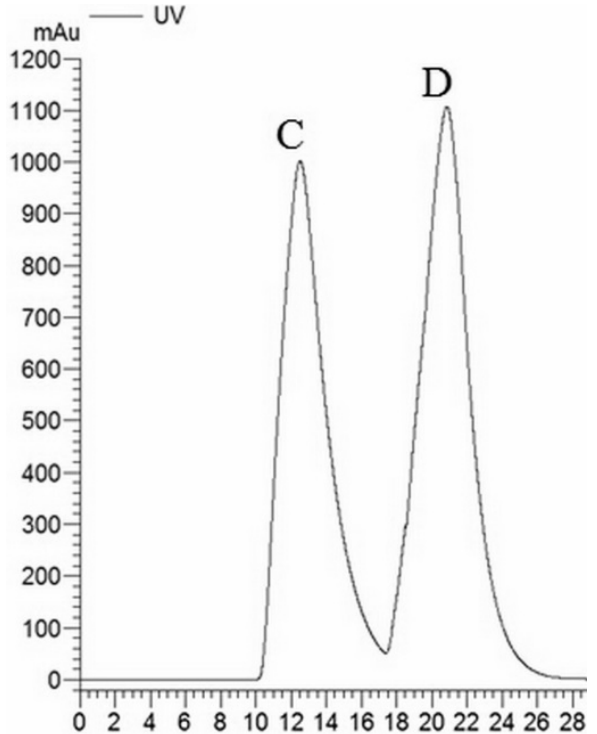

Figure 2: Gel filtration chromatogram. PBS (pH 7.4) was the elution buffer at $1 \mathrm{~mL} / \mathrm{min}$ flow velocity

\section{Activity of purified rhPA}

FAPA was applied to evaluate the thrombolytic bioactivity of purified rhPA in vitro, and the index was the diameter size of the fibrinolysis ring. As shown in Fig 3, well 10 contained the purified rhPA at a concentration of $1 \mu \mathrm{g} / \mathrm{mL}$, and the thrombolytic activity was presented with $24.0 \mathrm{~mm}$ diameter of the fibrinolysis ring. The purified rhPA $(1 \mu \mathrm{g} / \mathrm{mL}$ concentration) was presented with $24.0 \mathrm{~mm}$ diameter of the fibrinolysis ring of thrombolytic activity. A standard curve (Fig 3) was drawn using the concentrations of Alteplase, as follows: 5000, 1000, 200, 40, 8, 1.6, 0.32 and $0 \mu \mathrm{g} / \mathrm{mL}$. To reach the same thrombolytic effect of rhPA, the concentration of Alteplase was supposed to be $214 \mu \mathrm{g} / \mathrm{mL}$, which was much higher than the dose of purified rhPA. Thus, this purified rhPA displayed a 214-fold increase in activity to dissolve thrombus, compared with Alteplase by FAPA.

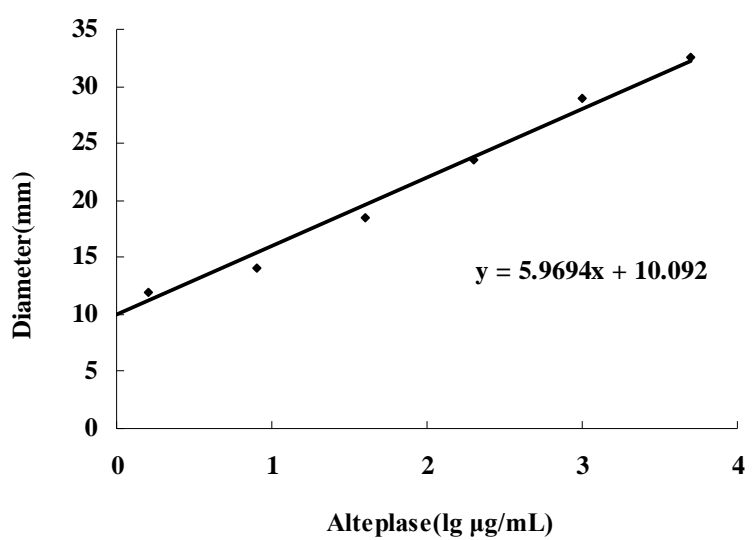

Figure 3: The standard curve of Alteplase in thrombolytic bioactivity. $X$-axis: the concentration of Alteplase (lg $\mu \mathrm{g} / \mathrm{mL}) ; Y$-axis: the diameter size of the fibrinolysis ring $(\mathrm{mm})$. The concentrations of Alteplase were 5000, 1000, 200, 40, 8, 1.6 and 0.32, $0 \mu \mathrm{g} / \mathrm{mL}$

\section{DISCUSSION}

rhPA is our originally designed mutant of tPA. This recombinant protein was produced by a bioreactor, rabbit mammary gland, which has advantages in natural molecular structure, protein amount, and safety. However, purification of the recombinant protein from milk is not an easy process [13]. Immunoaffinity chromategraphy is widely adopted, but the commonly used elution buffers often contain an acid agent or a chaotropic reagent, which would reduce the 
activity of target protein [14-16]. As for rhPA, its bioactivity relies on its protein structure. Therefore, a gentle method for purifying rhPA is necessary. In this study, immunoaffinity chromatography coupled with polyol responsive $\mathrm{mAb}$ was used. PR-mAbs as immunoaffinity ligands have been reported, and these presented good performance on RNA polymerase and RNA polymerase II [9-11,15]. However, these have not been used in the extraction for rabbit milk protein. This paper described the preparation for PR-mAbs and the application of the C4-PR-mAb in immunoaffinity chromatography for rhPA purification.

Three steps were required in this purification research. The first step involved extracting crude sample from rabbit milk, using salting out, ultrafiltration, and dialysis. The second step included immunoaffinity chromatography with C4-PR-mAb; rhPA and rhPA purity were not high. The other two bands appeared obviously (Fig. 1A). Thus, we initially suspected that C4PR-mAb crosslinked with other proteins and not only rhPA. However, the normal rabbit milk could not cross-react with the serum antibody of the immunized group, and this was also impossible for C4-PR-mAb (25 and $50 \mathrm{KDa}$ ). Therefore, if our first hypothesis was true, it would explain the following: except for rhPA, another novel protein was expressed by the transgenic rabbit. However, this explanation did not have a reliable basis. Fig $1 \mathrm{~A}$ was worth mentioning again. The band at $64 \mathrm{KDa}$ may have resulted from the combination of rhPA and the light chain of the antibody (39 KDa + $25 \mathrm{KDa}=64 \mathrm{KDa})$. The band at $50 \mathrm{KDa}$ may be the heavy chain of antibody $(50 \mathrm{KDa})$. This is not a coincidence because antibody ligand falling off column in affinity chromatography often occurred. Thus, in Fig 1B, the two fractions with negative reactivity for $\mathrm{C} 4$ PR-mAb may be related to the rhPA epitopes covered by the C4-PR-mAb ligand, which was detached from the column. rhPA with a single molecular was our objective. Thus, through Chromdex 75 prep grad gel filtration chromatography, these two bands were successfully removed, and a pure rhPA was ultimately obtained.

\section{CONCLUSION}

C4-PR-mAb is the key factor in this immunoaffinity purification for rhPA. rhPA is a novel recombinant mutant protein without $F, E$, and $\mathrm{K} 1$ structure domain, but the structure is similar to that of Alteplase. Based on this point, Alteplase is creatively selected as immunogen. The rhPA can be purified from transgenic rabbit milk through the above-described method, and it displayed 214-fold higher activity in dissolving thrombus than Alteplase. This process for antibody and purification development is our original design and helps us to determine rhPA PR-mAbs. Meanwhile, we successfully purified rhPA from milk. This method would be useful for other studies on similar novel recombinant proteins.

\section{ACKNOWLEDGEMENT}

This study was supported by the Priority Academic Program Development of Jiangsu Higher Education Institutions (PAPD), Jiangsu Co-innovation Center for Prevention and Control of Important Animal Infectious Diseases and Zoonoses, Graduate Research and Innovation Projects in Yangzhou University (CXLX-1435) and Jiangsu Province Science and Technology Support Project (BE2013679). We appreciate the technical assistance provided by Professor Yong-Cheng.

\section{CONFLICT OF INTEREST}

No conflict of interest associated with this work.

\section{CONTRIBUTION OF AUTHORS}

We declare that this work was done by the authors named in this article and all liabilities pertaining to claims relating to the content of this article will be borne by the authors.

\section{REFERENCES}

1. Nielsen VG, Matika RW, Ley ML, Waer AL, Gharagozloo $F$, Kim S, Nfonsam VN, Ong ES, Jie T, Warneke JA, Steinbrenner EB. Tissue-type plasminogen activatorinduced fibrinolysis is enhanced in patients with breast, lung, pancreas and colon cancer, Blood Coagul Fibrinolysis 2014; 25(3): 248-253

2. Collen D, Lijnen HR. The tissue-type plasminogen activator story, Arterioscler Thromb Vasc Biol 2009; 29(8): 1151-1155.

3. Obukowicz MG1, Gustafson ME, Junger KD, Leimgruber RM, Wittwer AJ, Wun TC, Warren TG, Bishop BF, Mathis KJ, McPherson DT. Secretion of active kringle-2serine protease in Escherichia coli, Biochem 1990; 29(41): 9737- 9745

4. Aflakiyan S, Sadeghi HM, Shokrgozar M, Rabbani M, Bouzari S, Jahanian-Najafabadi $A$. Expression of the recombinant plasminogen activator (reteplase) by a nonlytic insect cell expression system, Res Pharm Sci 2013; 8(1): 9-15

5. Denman J, Hayes M, O'Day C, Edmunds T, Bartlett $C$, Hirani S, Ebert KM, Gordon K, McPherson JM. 
Transgenic expression of a variant of human tissue-type plasminogen activator in goat milk: purification and characterization of the recombinant enzyme, Biotechnol 1991; 9(9): 839-843

6. Paleyanda RK, Velander WH, Lee TK, Scandella $D H$, Gwazdauskas FC, Knight JW, Hoyer LW, Drohan WN, Lubon $H$. Transgenic pigs produce functional human factor VIII in milk, Nat Biotechnol 1997; 15(10): 971-975

7. Suárez AM, Azcona JI, Rodríguez JM, Sanz $B$, Hernández PE. One-step purification of nisin $A$ by immunoaffinity chromatography, Appl Environ Microbiol 1997; 63(12):4990-4992

8. Thompson NE, Aronson DB, Burgess RR. Purification of eukaryotic RNA polymerase II by immunoaffinity chromatography. Elution of active enzyme with protein stabilizing agents from a polyol-responsive monoclonal antibody, J Biol Chem 1990; 265(12): 7069-7077

9. Thompson NE, Hager DA, Burgess RR. Isolation and characterization of a polyol- responsive monoclonal antibody useful for the gentle purification of Escherichia coliRNA polymerase, Biochemistry 1992; 31(30): 70037008

10. National Research Council (US) Institute for Laboratory Animal Research. Guide for the care and use of laboratory animals [J]. Guide for the Care \& Use of Laboratory Animals, 1974, 327(1): 41-48.

11. Bergendahl V, Thompson NE, Foley $K M$, Olson $B M$, Burgess RR. A cross-reactive polyol-responsive monoclonal antibody useful for isolation of core RNA polymerase from many bacterial species, Protein Expr Purif 2003; 31(1): 155-160

12. Stalder ES, Nagy LH, Batalla P, Arthur TM, Thompson $N E$, Burgess RR. The epitope for the polyol-responsive monoclonal antibody 8RB13 is in the flap-domain of the beta-subunit of bacterial RNA polymerase and can be used as an epitope tag for immunoaffinity chromatography, Protein Expr Purif 2011; 77(1):26-33

13. Wagner B, Robeson J, McCracken M, Wattrang E, Antczak DF. Horse cytokine/lgG fusion proteins-mammalian expression of biologically active cytokines and a system to verify antibody specificity to equine cytokines, Vet Immunol Immunopathol 2005; 105(1-2): 1-14

14. Edwards AM, Darst SA, Feaver WJ, Thompson NE, Burgess RR, Kornberg RD. Purification and lipid-layer crystallization of yeast RNA polymerase II, Proc Natl Acad Sci USA 1990; 87(6): 2122-2126

15. McElhiney J1, Drever M, Lawton LA, Porter AJ. Rapid isolation of a single-chain antibody against the cyanobacterial toxin microcystin-LR by phage display and its use in the immunoaffinity concentration of microcystins from water, Appl Environ Microbiol 2002; 68(11): 5288-5295

16. Edwards AM, Darst SA, Feaver WJ, Thompson NE, Burgess RR, Kornberg RD, Kornberg. Purification and lipid-layer crystallization of yeast RNA polymerase II, Proc Natl Acad Sci USA 1990; 87(6): 2122-2126 